\title{
Real Time Monitoring of Water Level Variations In Rivers and Flood Alerting System using Arm7
}

\author{
D. Mysar ${ }^{1}$, M. Jagadeesh babu ${ }^{2}$ \\ M. Tech Student, Dept of Electronics and Communication Engg, Madanapalle Institute of Technology \& Science, \\ Madanapalle, A.P, India $^{1}$ \\ Associate Professor, Dept of Electronics and Communication Engg, Madanapalle Institute of Technology \& Science, \\ Madanapalle, A.P, India ${ }^{2}$

\begin{abstract}
The main objective of this paper is monitor the water level variations in rivers and the monitored valued regularly stored in the web server which is useful to send flood alerts to corresponding authority for proper action and the same can be viewed through the web.

In this paper monitoring the water related data like water level and flow rate in rivers and flood conditions using a typical ARM 7 will process the data and GPRS/GSM SIM 900a module is used to transmit measured data to the database and application server. Sensors are distributed in rivers so that changes of the water level can be effectively monitored. The database and application server is implemented as a web-based application to allow users to view realtime water-related data as well as historical data. The application server is also able to send warnings to the responsible authorities in case of emergency.
\end{abstract}

Keywords: ARM 7, Sensors, GPRS/GSM Sim 900a module, Flood alerting System.

\section{INTRODUCTION}

Recently, there's been raising concern concerning the environment pitfalls as well as probable danger involving organic dilemmas, especially as a result of the particular development inside how many these kinds of occurrences. With India, the condition involving huge amounts is a huge certain root cause of alarm to culture.

The primary consequences involving water damage are materials, man, fiscal as well as interpersonal failures inside flooded parts, an infection through waterborne diseases as well as dirtied water. In addition to the pitfalls to life sustained simply by family members inside these kinds of parts, the particular fiscal deterioration has additionally imposed the responsibility of getting to recoup from their financial failures, without taking consideration the particular injury brought about to general public systems. So, you have to manage to notify the particular those who are the majority of vulnerable along with the general public systems involved, so the consequences of such dilemmas might be alleviated.

With this entire predicament, the particular overseeing involving river levels is critical. Even so, carrying out overseeing as a possible out of the way activity is not going to stop the particular man as well as financial failures. This involves a great investigation of the facts extracted from the particular overseeing together with the essence delivering the particular applicable data for the responsible systems in order that they are competent to forecast any time these kinds of functions are likely to occur. This may help those to help to make decisions using a watch to taking preventive procedures to lessen the particular intensity of the impacts as well as be sure that people vulnerable pick up enough alerts.
When considering this, this specific do the job suggests the usage of instant sensor sites over the river beds to keep track of the water levels and to sketch with this way to obtain data to help you the particular responsible systems as well as weak areas during the decision-making practice. Additionally, your method is founded on the particular "Sensor Web" paradigm, to be able to provide interoperability together with a variety of end-user geographical Software which can use up facts through consistent world wide web solutions.

\section{PROPOSED MODEL}

a)

Proposed Work:

The below shown the block diagram of proposed model. At first Flow Sensor, Temperature Sensor and three Raindrop Sensors connected to ARM7 Processor. This ARM7 Processor is connected to GPRS/GSM 900a modem and Buzzer.

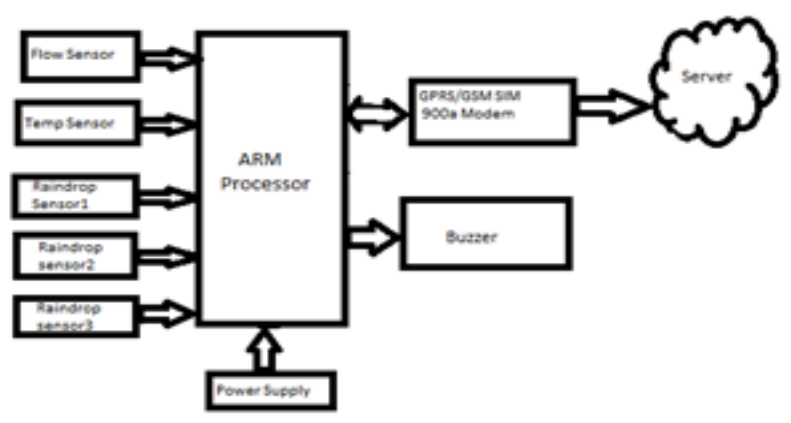

Fig 1: Block diagram of proposed model 
In this proposed model ARM7 is used for the processing a) unit.

Sensing Unit consists flow sensor, temperature sensor and rain drop sensor. Sensing unit senses the flow of water, temperature and its level. These kinds of files gathered and also transported within real-time on the complete riv container location multiple times each hour. Since the movement of your riv might change substantially over the amount of many units, this recommend the choosing pace for the buy associated with units. In order to help sent out, powerful, real-time files selection, sign, and also, at some point, processing for huge geographic locations equivalent to be able to authentic riv basins. Produce real-time connection associated with dimensions addressing numerous specifics causing the big event incidence. It minimizes the cost.

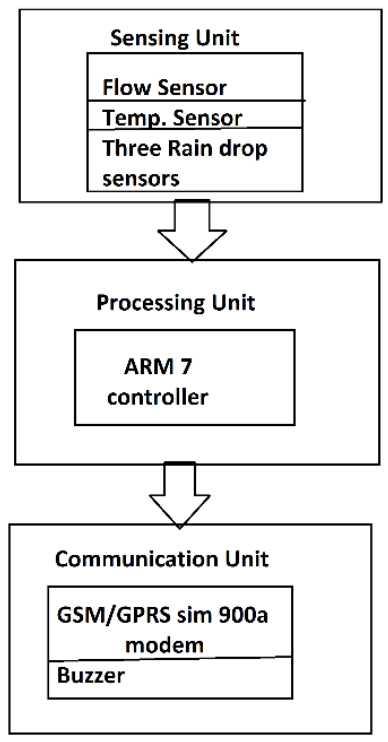

Fig 2: Processing Steps of Proposed Model

Processing unit receives the sensing data, these data is in analogue form. In built ADC in ARM Processor it converts analogue to digital do, don't need the external $\mathrm{ADC}$ in this unit. These processed data transmitted to communication unit.

Communication unit consists GSM/GPRS module and buzzer. A typical ARM 7 will process the data and transmission module is used to transmit measured data to the database and application server. The database and application server is implemented as a web-based application to allow users to view real-time water-related data as well as historical data. The application server is also able to send warnings to the responsible authorities in case of emergency.

\section{III.HARDWARE AND SOFTWARE REQUIREMENTS}

\section{A. Hardware Requirements:}

This project requires some hardware components such as ARM (Advanced Risk Machine), Flow Sensor, Temperature Sensor, Raindrop Sensor, GPRS and GSM.
ARM7:

The design of this project uses ARM7. ARM is a 32-bit reduced instruction set computer (RISC) instruction set architecture (ISA) developed by ARM Holdings. The ARM architecture is the most widely used 32-bit ISA in terms of numbers produced. The simplicity of ARM processors makes them suitable for low power applications. As a result, they have become dominant in the mobile and embedded electronics market, as relatively low-cost, small microprocessors and microcontrollers. This has meant an increasing dominance in the mobile and battery dependent electronics market, where the double advantages of respectable computing power coupled with low electrical power consumption are both desirable.

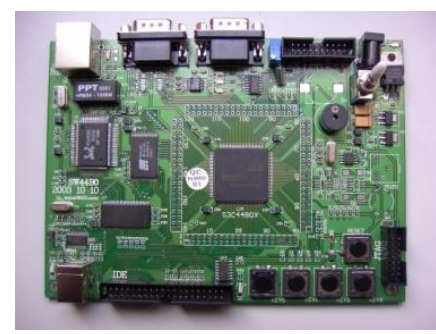

Fig3: ARM7 board

b) Flow Sensor

Flow sensor includes a plastic material device body, any water rotor, plus a hall-effect sensor. Any time water flows through the rotor, rotor rolls. Its speed changes with unique pace of flow. This hall-effect sensor outputs the particular similar heart signal. That one works to discover flow inside water dispenser.

This Popular feature of flow sensor is usually Compact, Easy to Mount, Higher Sealing Performance, Excellent Hall Effect Sensor in addition to RoHS Compliant.

Specifications of this Water Flow Sensor are

Mini voltage: DC $4.5 \mathrm{~V}-24 \mathrm{~V}$

Current: $15 \mathrm{~mA}$ (DC 5V)

Flow Rate Range: 1 to 30L/min

Load Capacity: 10mA (DC 5V)

Operating Temperature: $80-120$

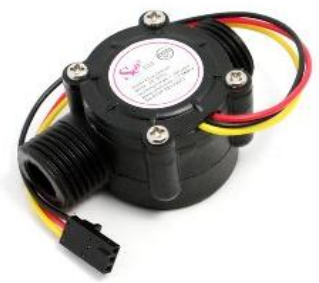

Fig 4: Flow Sensor

c) Temperature Sensor - LM 35

The design of this project uses temperature sensor LM 35 to measure temperature of the water. The features of temperature sensor are

Calibrated Directly in Celsius (Centigrade)

Rated for Full $-55^{\circ} \mathrm{C}$ to $150^{\circ} \mathrm{C}$ Range

Suitable for Remote Applications

Low-Cost Due to Wafer-Level Trimming

Operates from $4 \mathrm{~V}$ to $30 \mathrm{~V}$ 


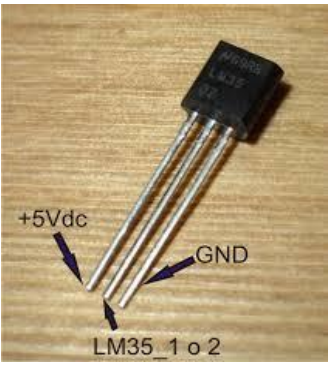

Fig 5: LM35 Temperature sensor

d) Rain Drop Sensor

Rain drop sensor used for measure the rain force.

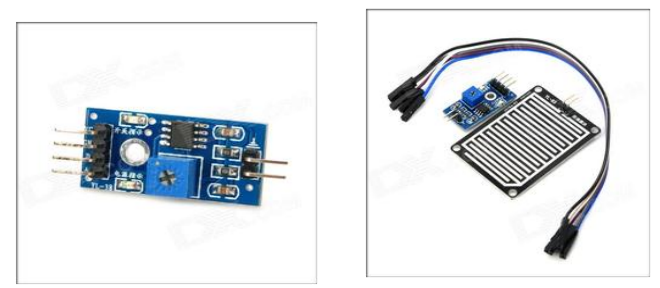

Fig6: Rain Drop Sensor

The key highlights of this particular Rainwater lower Sensor tend to be made for a myriad of weather conditions overseeing and will always be changed into electronic digital indication and output through OA.

Working voltage: $3.3-5 \mathrm{~V}$

VCC: $3-5 \mathrm{~V}$

GND: Negative electrode

DO: TTL switch signal output

AO: Analog signal output

\section{e) GSM/GPRS Modem}

GSM stands for Global System for Mobiles. This is an overall standard for advanced cell telephony, or as a great many people knows them Computerized Cellular Phones. GSM was made by the Europeans, and initially signified "Group Special Mobile", yet this didn't interpret well, so the now basic all the more all-around engaging name was embraced. GSM is a distributed standard by ETSI, and has now appreciates boundless usage in Europe, Asia, and progressively America. GSM architecture is shown in below Figure 7.

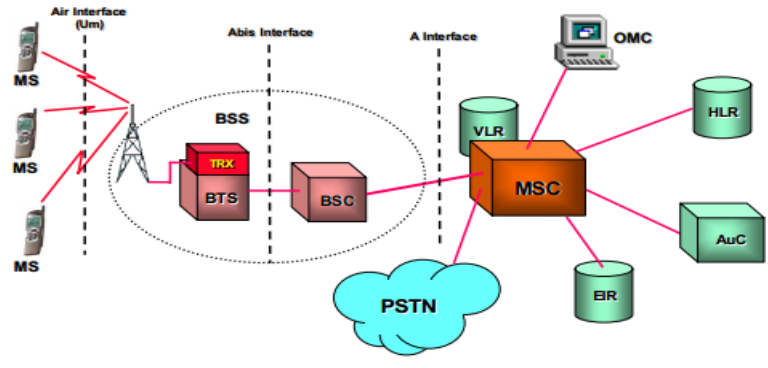

Fig7: GSM architecture

SIM 900a Modem

SIM stands for subscriber identity module. GSM/GPRS Modem-RS232 can be constructed using Double Wedding ring GSM/GPRS engine SIM900A, has a chance from frequencies 900/ $1800 \mathrm{MHz}$ your Modem can be enclosed
RS232 screen, that permits you sign up for COMPUTER and moreover microcontroller using RS232 Computer chip (MAX232). The actual baud price can be configurable coming from $9600-115200$ by means of IN buy. The actual GSM/GPRS Modem can be having within TCP/IP collection to empower that you join forces using web by means of GPRS. It really is made for TXT, Style and moreover Information shift software within M2M screen. The actual in your neighbourhood obtainable Aimed Power allows you to screen wide selection unregulated power supply. Using this particular modem, you may make voice cell phone calls, TXT, Study TXT; go to the incoming cell phone calls along with web act by means of essential IN summons [9]. Figure 4.10 shows diagram of SIM 900A modem.

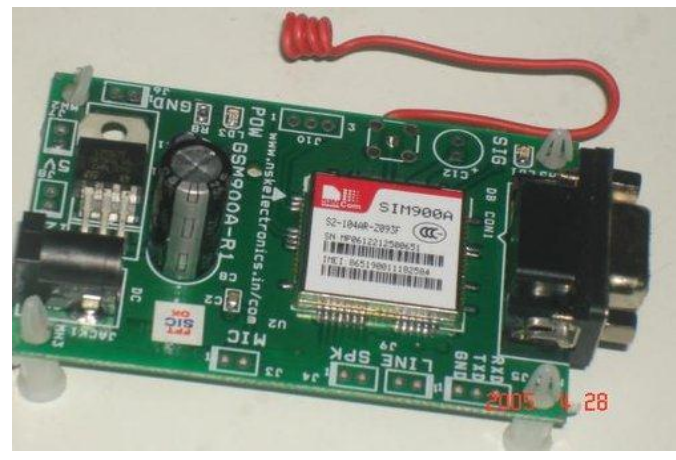

Fig8: SIM 900A modem

f) Buzzer

Piezo buzzer is the handy sound generator used in electronic circuits to give audio indication .It is widely used as alarm generator in electronic devices. It is available in various types and size to suit the requirements. A Piezo buzzer has a Piezo disc and an oscillator inside. When the buzzer is powered, the oscillator generates a frequency around $2-4 \mathrm{kHz}$ and the Piezo element vibrates accordingly to produce the sound. An ordinary Piezo buzzer works between $3-12$ volts DC.

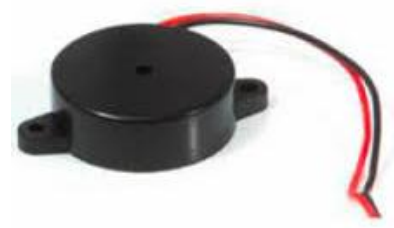

Fig9: Buzzer

g) power supply

LPC2148 is offers high performance and very low power consumption.ARM7 consists of dual power supply either through USB or external power adapter. It works three on board voltage regulators $1.8 \mathrm{~V}, 3.3 \mathrm{~V}$, and $5 \mathrm{~V}$ with up to 800ma current.

h) Software implementation:

Software implementation of this work uses Keil software and Flash magic utility.

a) Keil:

Keil compiler is software used where the machine language code is written and compiled. After compilation, 
the machine source code is converted into hex code which is to be dumped into the microcontroller for further processing. Keil compiler also supports $\mathrm{C}$ language code.

\section{b) Flash Magic:}

Utilizing Flash Magic, you can perform diverse operations to a microcontroller gadget, operations like eradicating, programming and perusing the glimmer memory, altering the Boot Vector, performing a free ticket to ride on an area of the Flash memory and numerous others.

\section{IV.EXPERIMENTAL RESULTS}

Our strategy has been used using one particular sensor node as a way to keep an eye on lake. This way, information in regards to the drinking water amount of your lake might be exhibited instantly from the program. Additionally, the internet program likewise gifts maps using the evolution on the drinking water amounts. Figure 10 demonstrates your planned product package put next to lake.

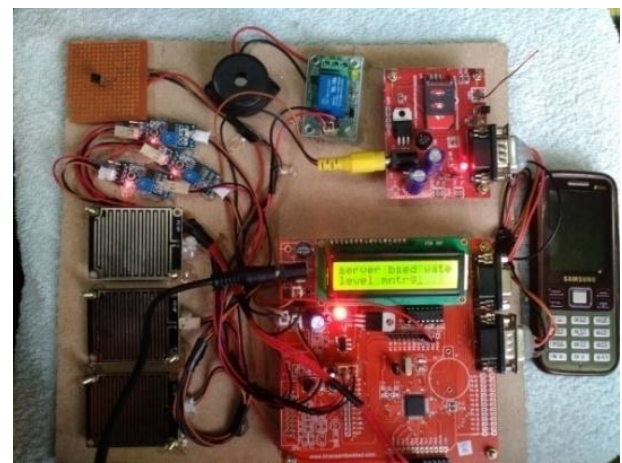

Fig 10: Proposed model

We place three Rain drop sensors in rivers in three levels at $35 \%, 70 \%$ and $90 \%$ of water level. The water level is below 35\% proposed model shows temperature of water and flow as LOW FLOW. This figure is shown below

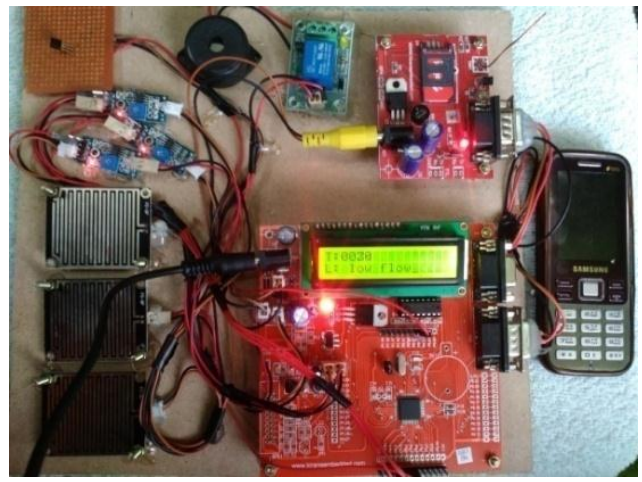

Fig 11: Output below $35 \%$ of water level

When water level reaches $35 \%$ means water reaches Rain drop sensor 1, output of the proposed model gives temperature and Flow percentage. It also sends the message to corresponding authority. This figure is shown below

When water level reaches $90 \%$ means water reaches Rain drop sensor 3, output of the proposed model gives temperature and Flow percentage.

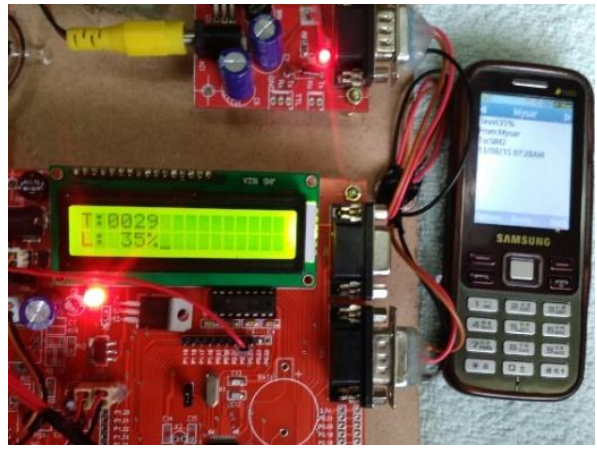

Fig 12: Output above $35 \%$ of water level

When water level reaches $70 \%$ means water reaches Rain drop sensor 2, output of the proposed model gives temperature and Flow percentage. It also sends the message to corresponding authority. This figure is shown below

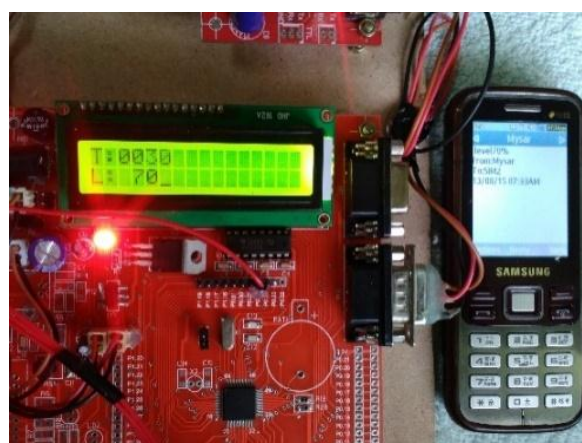

Fig 13: Output water level reaches $70 \%$

It also sends the message to corresponding authority. This figure is shown below

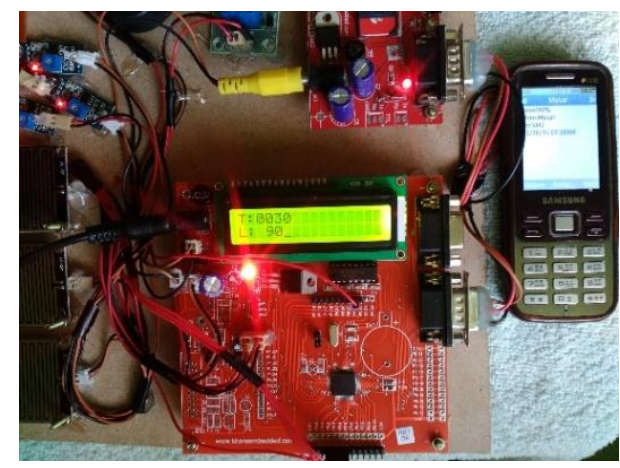

Fig 14: Output water level reaches $90 \%$

When water level reaches $90 \%$, the buzzer rings for urgent alerts. The graph shows relation of different times and flow of water.

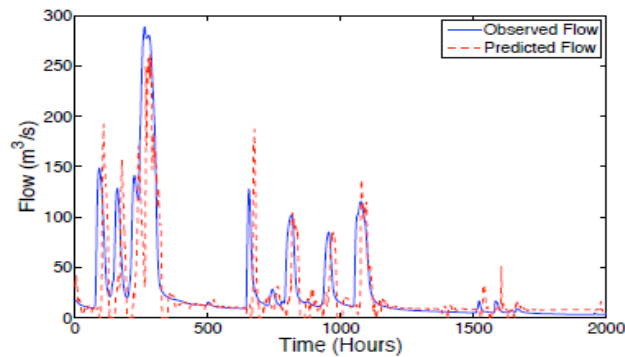

Fig 15: Relation between different times and flow of water 
In all these water levels processing unit sends the information to web through GSM/GPRS module. Web page is shown below

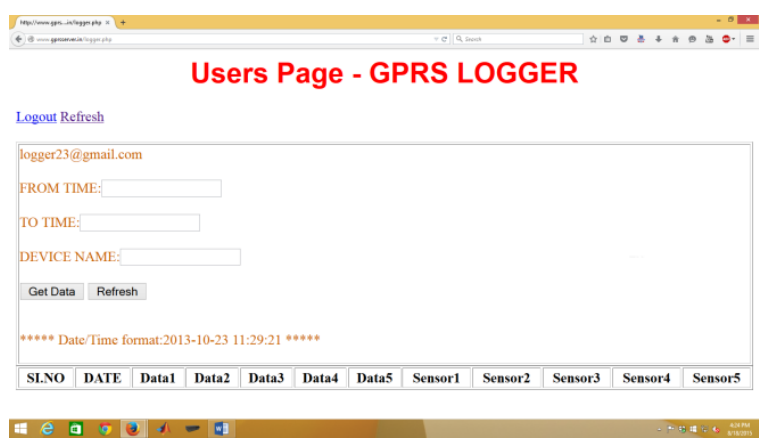

Fig 16: Web page

Received data is displayed it the web page from GSM/GPRS is shown below

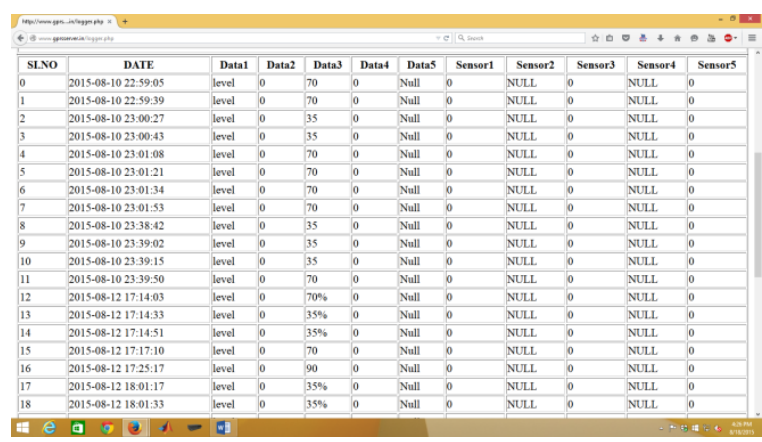

Fig 17: Received data in Web page.

\section{CONCLUSION}

In this paper a model of the Real-Time monitoring of water level variations in rivers and flood alerting system using ARM7 is developed. Sensors and wireless communication protocols have been used to create a database and application server. ARM7 does the analog to digital conversion between sensors and GPRS/GSM module, which are in the form of a single unit called a node that combines all these sensors, an ARM processor, and a GPRS/GSM module. In this study one node is achieved with low consumption of power. Whenever monitoring the large geographic river basins, dams, reservoirs etc., and these nodes can extend like 10, 20 to monitor the Real time data and also historical data.

\section{ACKNOWLWDGEMENT}

I got success in completing this work by the extreme guidance of my guide and parents. I thanks to them.

\section{REFERENCES}

[1] Chang, N. and Guo Da-Hai. 2006. Urban Flash Flood Monitoring, Mapping and Forecasting via a Tailored Sensor Network System, Proceedings of the 2006 IEEE International Conference on Networking, Sensing and Control 2006, issue 23-25, pp. 757-761, April 2006.
[2] H.LCloke, F.Pappenberger "Ensemble flood forecasting: A review" Elsevier Journal of Hydrology, vol. 375, pp.613 626, September 2009.

[3] L.Alfieri, J.Thielen, F.pappenberger", Ensemble hydrometrological simulation for flash flood early detection", Elsevier Journal of hydrology, vol. 424-425, pp.143-153, March 2012.

[4] S.Rozalis,E.Morin,Y.Yair,C.Price,'Flash Flood Prediction using an uncelebrated hydrological model and radar rainfall data in a Mediterranean watershed under changing hydrological conditions" Elsevier Journal of Hydrology,vol.394, pp.245-255,2010.

[5] B.Biondi,D.L.D.Luca, "Performance assessment of a Bayesian Forecasting System (BFS) for real time flood forecasting" Elsevier Journal of Hydrology, vol.479, pp.51-63, 2013.

[6] Adinya John Odey, Daoliang Li, Wireless Sensor Network, 2012, 4 , 243-249 http://dx.doi.org/10.4236/wsn.2012.410035 Published Online October 2012

[7] Danny Hughes, Phil Greenwood, Gordon Blair, Geoff Coulson, Florien Pappenberger, Paul Smith and Keith Beven, An Intelligent and Adaptable Grid-based Flood Monitoring and Warning System,

8] SIVA KUMAR SUBRAMANIAM VIGNESWARA RAO GANNAPATHY ,SIVARAO SUBRAMONIAN and ABDUL HAMID HAMIDON, Flood level indicator and risk warning system for remote location monitoring using Flood Observatory System SEAS TRANSACTIONS on SYSTEMS and CONTROL ISSN: 1991-8763 Issue 3, Volume 5, March 2010

[9] Jialong Sunkpho and Chaiwat Ootamakorn Real-time flood monitoring and warning system Songklanakarin J. Sci. Technol. 33 (2), 227-235, Mar. - Apr. 2011.

[10] Lívia C. Degrossi, Guilherme G. do Amaral, Eduardo S. M. de Vasconcelos, Using Wireless Sensor Networks in the Sensor Web for Flood Monitoring in Brazil, Degrossi et al. Wireless Sensor Networks for Flood Monitoring in Brazil10th International ISCRAM Conference - Baden-Baden, Germany, May 2013

\section{BIOGRAPHIES}

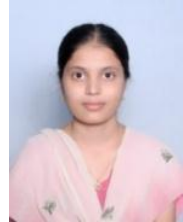

D.Mysar pursuing M.Tech in ECE with Specialization digital Electronics and communication systems from Madanapalle Institute of Technology and Science, Madanapalle Affiliated to JNTUA.

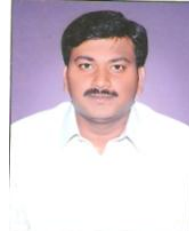

M.JAGADEESH BABU (Ph.D.) working as an Associate Professor in Madanapalle Institute of Technology and Science, Madanapalle. 